\title{
Immunological Studies of Aging
}

\author{
DECREASED PRODUCTION OF AND RESPONSE TO T CELL GROWTH \\ FACTOR BY LYMPHOCYTES FROM AGED HUMANS
}

\author{
Steven Gillis, Robert Kozak, Michael Durante, and Marc E. Weksler, \\ Department of Developmental Hematopoiesis, Memorial Sloan Kettering \\ Cancer Center, and Department of Medicine, Cornell University Medical College, \\ New York 10021
}

\begin{abstract}
A B S T R A C T Human lymphocytes from elderly and young donors were cultured with phytohemagglutinin (PHA) or concanavalin A. Cultures from old donors produced less $\mathrm{T}$ cell growth factor (TCGF) and incorporated less tritiated thymidine $\left({ }^{3} \mathrm{H}-\mathrm{Tdr}\right)$ than did similar cultures from young donors in the presence of either mitogen. Furthermore, the response of lymphocytes from elderly donors to TCGF was impaired. Thus, PHA-activated $T$ cells from aged donors showed no increase tritiated thymidine incorporation when incubated with exogenous human TCGF. In contrast, addition of exogenous human TCGF to PHA-activated peripheral blood leukocytes from younger individuals increased tritiated thymidine incorporation by $30-50 \%$. The impaired response to TCGF was associated with decreased binding of TCGF by PHA-activated cells from old donors. TCGF production or responsiveness was not associated with the presence of "suppressor" activity in elderly $\mathrm{T}$ cell preparations. These studies suggest a possible molecular mechanism for the impaired proliferative response of elderly human $\mathrm{T}$ cells. These data lend support to the hypothesis that defects in the capacity to either produce or respond to TCGF may be a fundamental cause of immune deficiency.
\end{abstract}

\section{INTRODUCTION}

Lymphocytes from human donors $>65$ yr of age incorporate less thymidine when stimulated in culture with plant lectins than do lymphocytes from young individuals (1). The reason for the impaired proliferation of $T$ cells from old people has not been defined. The relative and absolute number of $\mathrm{T}$ and $\mathrm{B}$ cells are not sig-

Dr. Gillis is a Fellow of the Leukemia Society of America. $\mathrm{His}$ current address is Basic Immunology Program, Fred Hutchinson Cancer Research Center, Seattle, Wash. 98104.

Received for publication 16 June 1980 and in revised form 21 November 1980. nificantly altered with age although changes in the T-gamma and $\mathrm{T}$-mu subpopulations have recently been reported (2). A detailed analysis (3) of the cellular basis of the impaired proliferative response of $T$ cells from aged individuals suggested that two factors contributed to the proliferative defects: $(a)$ a reduction in the number of mitogen-responsive $T$ cells in the blood of elderly persons and $(b)$ a failure of the mitogen responsive cells to proliferate normally in culture.

Recent studies have revealed that mitogen-induced proliferation of murine and human $T$ lymphocytes in culture is driven by $\mathrm{T}$ cell growth factor (TCC.F). ${ }^{1}$ The proliferation of lymphocytes depends on their capacity to produce and respond to TCGF (4-6). Mitogens stimulate a subset of mature $T$ cells (in collaboration with adherent mononuclear cells) to produce and release TCGF. A second subset of $T$ lymphocytes rendered TCGF-responsive by the mitogen, binds TCGF and proliferatives $(6,7)$. The progeny of the TCGF-responsive $T$ cells remain TCGF sensitive, allowing for their exponential in vitro culture simply by the continuous addition of TCGF $(4,8)$. Little evidence to date suggests that TCGF-producer $\mathrm{T}$ cells proliferate in response to TCGF.

In this report we present evidence that phytohemagglutinin (PHA)- and concanavalin A (Con A)-stimulated lymphocytes from elderly people produce less TCGF than do lymphocytes from young people cultured in an identical fashion. Furthermore, we found that lymphocytes from elderly people are less responsive to TCGF. These findings may explain, at least in part, the impaired proliferative response of lymphocytes from aged humans.

\footnotetext{
${ }^{1}$ Abbreviations used in this paper: Con A, concanavalin A ${ }^{3} \mathrm{H}-\mathrm{Tdr}$, tritiated thymidine; $\mathrm{PBL}$, peripheral blood leukocytes; PHA, phytohemagglutinin; TCGF, T cell growth factor.
} 


\section{METHODS}

Assays for TCGF production and mitogen-induced proliferation. Mononuclear leukocytes (PBL) from elderly (67-81 yr) and young (21-30 yr) donors were isolated from peripheral blood samples by ficoll-hypaque density sedimentation using procedures previously described (4). Separated cells $\left(1 \times 10^{6}\right.$ cells $\left./ \mathrm{ml}\right)$ were resuspended in Click's medium (supplemented with $10 \%$ heat-inactivated $\left(56^{\circ} \mathrm{C}\right.$ for $30 \mathrm{~min}$ ) fetal calf serum, $25 \mu \mathrm{M} / \mathrm{ml}$ HEPES buffer, $16 \mu \mathrm{M} / \mathrm{ml}$ $\mathrm{NaHCO}_{3}, 50 \mathrm{U} / \mathrm{ml}$ penicillin, $50 \mu \mathrm{g} / \mathrm{ml}$ streptomycin and 300 $\mu \mathrm{g} / \mathrm{ml}$ fresh L-glutamine) and stimulated in replicate $200-\mu \mathrm{l}$ cultures (No. 3096 flat-bottom microtiter plates, Costar Data Packaging, Cambridge, Mass.) with either (a) tissue culture medium, $(b)$ Con A $(10 \mu \mathrm{g} / \mathrm{ml}),(c)$ PHA ( $1 \%$ by volume, Gibco Laboratories, Grand Island Biological Co., Grand Island, N. Y.) or $(d)$ purified human TCGF to which a mitogenic dose of PHA had been added. Human TCGF was produced from 48-h tissue culture medium conditioned by the PHA (1\%) and alloantigen stimulation of $\mathrm{PBL}$ using procedures detailed elsewhere (4). Purified TCGF used in these studies was prepared by sequential $85 \%$ ammonium sulfate precipitation, Sephadex G-100 gel filtration chromatography, and diethylaminoethyl cellulose ion exchange chromatography using previously detailed methods $(9,10)$. After various time periods (see Results) $100 \mu \mathrm{l}$ of supernatant fluid from stimulated cultures was removed and tested for the presence of TCGF activity. To assess cellular proliferation the identical cultures were pulsed for $4 \mathrm{~h}$ with tritiated thymidine $\left({ }^{3} \mathrm{H}-\mathrm{Td}, 0.5 \mu \mathrm{Ci} /\right.$ well, $20 \mathrm{Ci} /$ $\mathrm{mM}$, New England Nuclear, Boston, Mass.) and harvested onto glass fiber filter strips with the aid of a multiple automated sample harvester. Incorporated thymidine was counted by liquid scintillation and cellular proliferation was expressed in terms of mean cpm $\pm 1 \mathrm{SD}$ of triplicate cultures. In experiments designed to determine whether poor TCGF production and proliferation exhibited by lymphocytes from elderly patients was the result of overabundance of suppressor cells, populations of both old and young cells were mixed 1:1 (final concentration $10^{6}$ cell $/ \mathrm{ml}$ ) before testing.

TCGF microassay. Supernatant fluids harvested from cultures of both resting and stimulated PBL were tested for TCGF activity by their ability to sustain the proliferation of murine cytotoxic $\mathrm{T}$ cells harvested from long-term TCGF-dependent cultures (CTLL) (8). Using methods previously described (11), 3,000 CTLL cells were cultured for $24 \mathrm{~h}$ in 200 $\mu \mathrm{l}$ vol of supplemented Click's medium in the presence of a $\log _{2}$ dilution series of a given putative TCGF-containing sample. After a subsequent 4 -h pulse with ${ }^{3} \mathrm{H}-\mathrm{Tdr}(0.5 \mu \mathrm{Ci} /$ well $)$ it is routinely observed that only CTLL cells cultured in the presence of TCGF incorporate ${ }^{3} \mathrm{H}-\mathrm{Tdr}$ in a dose-dependent manner (11). Cells cultured in the absence of TCGF are $>95 \%$ trypan blue positive and incorporate only scintillant control levels of ${ }^{3} \mathrm{H}$-Tdr. TCGF activity was quantified by means of probit analysis (11) of incorporation data which used as a $1-\mathrm{U} / \mathrm{ml}$ standard, a preparation of TCGF generated by the $48-\mathrm{h}$ Con A stimulation of rat splenocytes $\left(10^{6} / \mathrm{ml}\right)$.

Quantitative absorption trials. The ability of a particular cell population to respond to a TCGF stimulation is dependent on the acquisition of cell surface TCGF receptors $(5-7,12,13)$. Receptor number and/or affinity of lymphocyte populations can be determined either by their ability to bind radiolabeled purified TCGF (13) or by their ability to absorb purified TCGF from solution $(6,7,12,13)$.

Relative abilities of both old and young PHA-activated PBL to bind TCGF were examined in quantitative absorption trials. 95-100\% viable blasts harvested from 48-h PHA-stimulated cultures (separated via ficoll-hypaque sedimentation) were washed extensively and adjusted to various cell concen- trations ranging from $3 \times 10^{5}$ to $3 \times 10^{7}$ cells $/ \mathrm{ml}$ in a given amount of purified human TCGF. After a 4 -h incubation at either $37^{\circ}$ or $4^{\circ} \mathrm{C}$, cells were centrifuged $(300 \mathrm{~g}$ for $10 \mathrm{~min})$ and the supernatant fluid was tested for remnant TCGF activity. Absorption capacity determined at multiple cell concentrations was expressed in terms of the percentage of TCGF activity remaining after warm $\left(37^{\circ}\right)$ or cold $\left(4^{\circ} \mathrm{C}\right)$ absorption.

\section{RESULTS}

TCGF production by lymphocytes from old and young donors. To determine whether the impaired $\mathrm{T}$ lymphocyte proliferation of elderly individuals was related to a defect in TCGF production, PBL from 10 old $(67-81 \mathrm{yr})$ and 7 young $(21-30 \mathrm{yr})$ donors were studied in five separate experiments. In each study, young and old lymphocytes were cultured in microwells with mitogenic doses of either Con A or PHA. After $48 \mathrm{~h}$ of culture half of the micro-well supernatant fluid $(0.1 \mathrm{ml})$ was removed and the TCGF activity determined. Replicate cultures were incubated for an additional $24 \mathrm{~h}$, after which they were pulsed for $4 \mathrm{~h}$ with ${ }^{3} \mathrm{H}-\mathrm{Tdr}$ to determine mitogen-induced cellular proliferation. The results of these experiments are presented in Table I. Lymphocytes from elderly donors incorporated significantly less $(P<0.001)^{3} \mathrm{H}-\mathrm{Td}$ r than did lymphocytes from younger subjects. Similarly, supernatant fluids from elderly lymphocyte cultures incubated for $48 \mathrm{~h}$ with mitogen contained significantly lower activity of TCGF $(P<0.001)$ than did supernatant fluids from young lymphocyte cultures.

In each experiment the proliferation of lymphocytes from elderly subjects incubated with Con A or PHA after 24 or $48 \mathrm{~h}$ of culture was also significantly lower $(P<0.001)$ than that of young lymphocytes. Because TCGF is the driving force for $\mathrm{T}$ cell proliferation, we chose to show proliferation and TCGF concentration at the time points where each parameter reached its peak respective value $(72 \mathrm{~h}$ for maximum ${ }^{3} \mathrm{H}-\mathrm{Tdr}$ incorporation, $48 \mathrm{~h}$ culture supernatant fluids for maximal TCGF activity). Accordingly, although TCGF present in 72-h culture supernatant fluids of elderly PBL was significantly less than factor concentrations present in cultures of identically activated young PBL $(P<0.001)$, their numerical values were lower than those observed $24 \mathrm{~h}$ earlier. These findings agree with previous studies indicating that the TCGF activity in supernatant culture medium results from a delicate balance between the amount of factor produced and that consumed by activated $T$ cells $(5-7,11,12)$.

Response of lymphocytes from old and young subjects to exogenous TCGF. The close linear correlation between ${ }^{3} \mathrm{H}-\mathrm{Tdr}$ incorporation and TCGF production by mitogen-activated PBL from old and young subjects (shown in Fig. 1) was consistent with previous studies which have investigated the relationships between 
TABLE I

Summary of TCGF Production and ${ }^{3} \mathrm{H}-\mathrm{T} d \mathrm{I}$ Incorporation by PBL from Old and Young Donors

\begin{tabular}{|c|c|c|c|c|c|c|}
\hline & \multicolumn{6}{|c|}{ Culture stimulant } \\
\hline & \multicolumn{2}{|c|}{ None } & \multicolumn{2}{|c|}{ Con $\mathrm{A}$} & \multicolumn{2}{|c|}{ PHA } \\
\hline & $\begin{array}{c}{ }^{3} \mathrm{H}-\mathrm{Td} \mathbf{d r} \\
\text { incorporation }\end{array}$ & $\begin{array}{l}\text { TCGF } \\
\text { activity }\end{array}$ & $\begin{array}{c}{ }^{3} \mathrm{H}-\mathrm{Td} \mathrm{dr} \\
\text { incorporation }\end{array}$ & $\begin{array}{l}\text { TCGF } \\
\text { activity }\end{array}$ & $\begin{array}{c}{ }^{3} \mathrm{H}-\mathrm{Td} \mathbf{r} \\
\text { incorporation }\end{array}$ & $\begin{array}{l}\text { TCGF } \\
\text { activity }\end{array}$ \\
\hline Aged donors $(10) \downarrow$ & $0.6 \pm 0.3$ & $0.0 \pm 0.0$ & $36.2 \pm 10.1$ & $2.1 \pm 0.9$ & $73.8 \pm 21.9$ & $3.4 \pm 1.6$ \\
\hline Young donors (7) & $0.5 \pm 0.3$ & $0.0 \pm 0.0$ & $81.6 \pm 17.2$ & $5.3 \pm 0.9$ & $116.2 \pm 11.5$ & $8.9 \pm 2.2$ \\
\hline $\begin{array}{l}\text { Significance of difference } \\
\text { between old and young } \\
\text { PBL response }\end{array}$ & NS & NS & $P<0.001$ & $P<0.001$ & $P<0.002$ & $P<0.001$ \\
\hline
\end{tabular}

* Lymphocytes from aged or young donors were cultured in media, media containing $10 \mu \mathrm{g} / \mathrm{ml} \mathrm{Con} \mathrm{A,} \mathrm{or} \mathrm{media}$ containing $1 \%$ PHA. TCGF and ${ }^{3} \mathrm{H}-\mathrm{Td}$ incorporation was measured as described in Methods.

$\$$ Number of individuals tested in parentheses.

TCGF production and resultant activated T cell proliferation. For example, glucocorticoid hormone-induced suppression of mitogen-activated human $\mathrm{T}$ cell replication was previously shown to be directly proportional to the inhibition of TCGF production $(14,15)$. Based on the data detailed in Table $I$ and Fig. 1 it appeared that, in part, the meager lymphoproliferative responses of elderly $T$ cells was due to an impaired production of TCGF.

The capacity of exogenous TCGF to correct the pro-

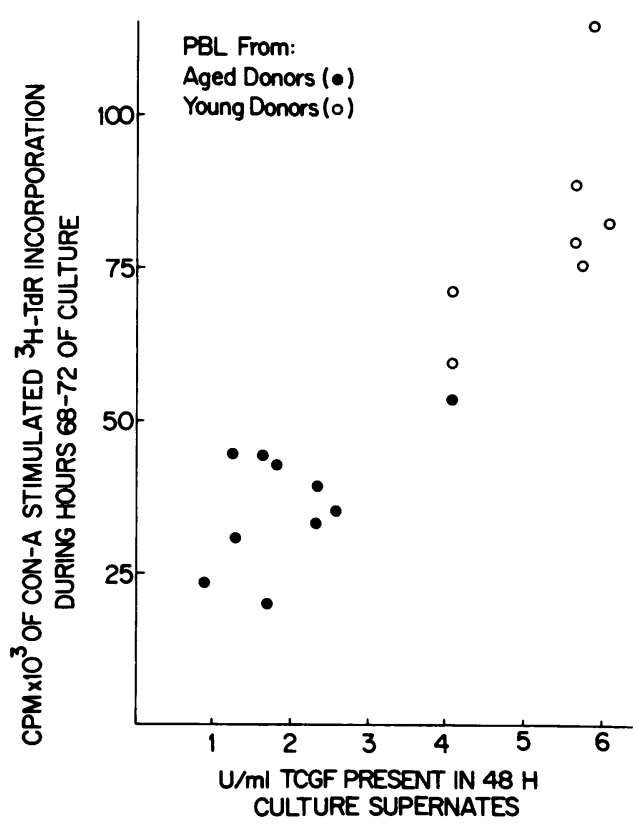

FIGURE 1 Lymphocytes from 7 young and 10 old individuals were cultured with Con $A$. The concentration of TCGF in the supernatant fluid after $48 \mathrm{~h}$ and ${ }^{3} \mathrm{H}$ - Tdr incorporation after $72 \mathrm{~h}$ was measured. Correlation between concentration of TCGF Activity and ${ }^{3} \mathrm{H}-\mathrm{Tdr}$ incorporation is presented. PBL from aged donors $(\Theta)$; young donors $(\bigcirc)$. liferative defect of lymphocyte from old donors was tested. Lymphocytes were cultured with mitogenic concentrations of PHA either alone or with purified human TCGF $(1 \mathrm{U} / \mathrm{ml})$. After $3 \mathrm{~d}$ the cultures were pulsed with ${ }^{3} \mathrm{H}-\mathrm{Tdr}$ to assess cellular proliferation. As shown in Fig. 2, PHA-activated PBL from each of the seven young donors incorporated significantly more ${ }^{3} \mathrm{H}-\mathrm{Tdr}$ in

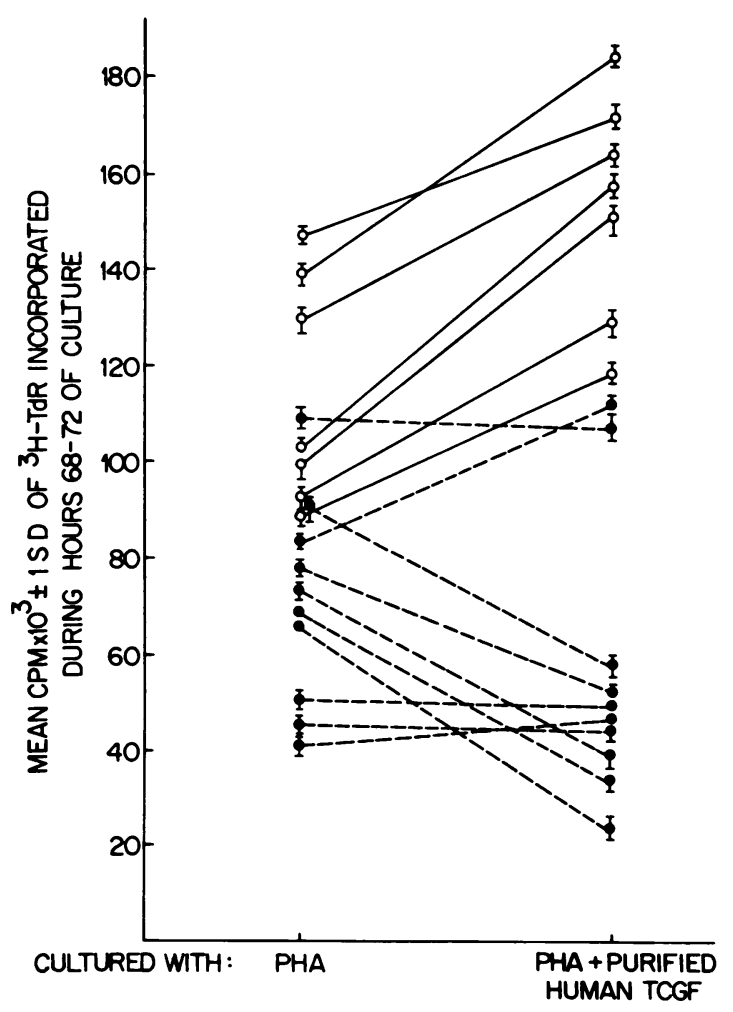

FIGURE 2 Lymphocytes from young and old individuals were cultured with PHA alone or with PHA and $1 \mathrm{U} / \mathrm{ml}$ of TCGF. ${ }^{3} \mathrm{H}$-Tdr incorporation by lymphocytes was measured after $68 \mathrm{~h}$ incubation. PBL from aged donors $(\bullet)$; young donors $(\bigcirc)$. 
the presence of the exogenous TCGF as compared with cells stimulated solely with PHA. The mean increase in ${ }^{3} \mathrm{H}$ - $\mathrm{Tdr}$ incorporation observed was $36 \pm 6.8 \%$. In contrast, PHA-stimulated PBL from only 2 of 10 elderly donors demonstrated increased ${ }^{3} \mathrm{H}-\mathrm{T} d r$ incorporation in the presence of exogenous TCGF. Lymphocytes from eight elderly donors showed either no change or a decrease in ${ }^{3} \mathrm{H}$-Tdr incorporation after $72 \mathrm{~h}$ in culture in the presence of PHA and TCGF compared to identical cultures stimulated by PHA alone. As lymphocytes from old donors do not interact with TCGF normally (see below), it was possible that larger amounts of TCGF might be necessary to drive lymphocyte proliferations. Incubation with 5- to 20-fold larger amounts of TCGF did not augment but inhibited the proliferation of lymphocytes from old donors (Table II).

The ability of an activated T-cell population to proliferate in response to TCGF has previously been found to be related to the capacity of the activated cells to remove TCGF from culture medium $(6,7,12)$. Antigen or mitogen-activated $T$ cell populations can absorb TCGF after short incubations at $4^{\circ} \mathrm{C}$ or $37^{\circ} \mathrm{C}$, whereas lymphocytes not previously activated do not absorb TCGF $(6,7,12,13,16)$. The capacity of lymphocytes from old and young donors to bind TCGF was investigated. Viable PHA-induced lymphoblasts from elderly or young donors were collected by density sedimentation and adjusted to identical cell concentrations. The ability of these cells to absorb a known concentration of TCGF was tested during a 4-h incubation at either $37^{\circ}$ or $4^{\circ} \mathrm{C}$. As shown in Fig. 3, at either temperature, PHA blasts prepared from young donors were far more efficient in absorbing TCGF than were activated $T$ cells prepared from elderly individuals. For example, at $37^{\circ} \mathrm{C}$, PHA-activated lymphocytes from young donors $\left(7.5 \times 10^{6}\right.$ cells $\left./ \mathrm{ml}\right)$ removed $88 \%$ of the TCGF activity present. Identical concentrations of PHAactivated lymphocytes from elderly donors absorbed

TABLE II

Response of PBL from Young or Old Donors to TCGF

\begin{tabular}{lcccc}
\hline & \multicolumn{4}{c}{$\begin{array}{c}{ }^{3} \mathrm{H}-\mathrm{Tdr} \text { Incorporation by lymphocytes in presence } \\
\text { of PHA and TCGF }\end{array}$} \\
\cline { 2 - 5 } Donor & No TCGF & 1 U/ml TCGF & 5 U/ml TCGF & 20 U/ml TCGF \\
\hline Y-APB & 125.6 & 165.7 & 198.0 & 210.7 \\
Y-JC & 108.6 & 146.2 & 166.2 & 171.2 \\
Y-PCK & 146.4 & 181.5 & 190.0 & 212.2 \\
A-JH & 72.3 & 61.1 & 59.0 & 55.4 \\
A-CH & 81.6 & 71.6 & 66.5 & 63.4 \\
A-GTB & 53.0 & 41.4 & 43.5 & 41.1 \\
\hline
\end{tabular}

* Lymphocytes from young (Y) or aged (A) donors were incubated with $1 \%$ PHA for $72 \mathrm{~h}$ in the presence or absence of TCGF $\left(\mathrm{cpm} \times 10^{-3}\right)$. ${ }^{3} \mathrm{H}-\mathrm{Tdr}$ incorporation was measured between 68 and $72 \mathrm{~h}$.

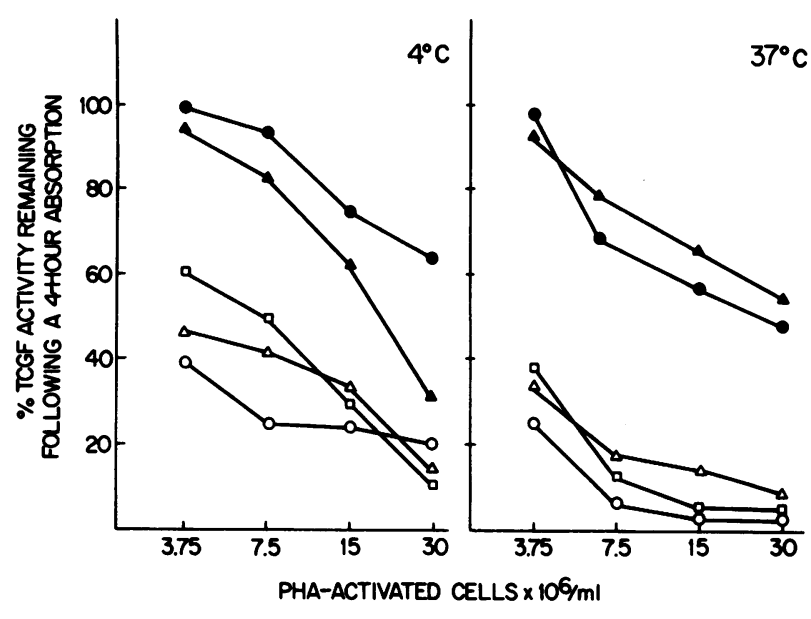

FIgURE 3 Varying numbers of PHA-induced lymphoblasts were incubated with $4 \mathrm{U} / \mathrm{ml}$ of TCGF for $4 \mathrm{~h}$ at $4^{\circ}$ or $37^{\circ} \mathrm{C}$. The percentage of TCGF remaining in the supernatant medium was determined after the incubation period. Closed symbols represent cultures with cells from two old subjects. Open symbols represent cultures from three young subjects.

only $20-40 \%$ of the TCGF present. These results suggested that lymphocytes from old individuals were impaired in their capacity to bind TCGF receptor sites on activated $T$ cells from elderly donors or changes in the affinity of these receptors must await the development and application of radiolabeled TCGF binding assays.

Lymphocytes from elderly donors do not suppress TCGF production by PBL from young donors. It was possible that the low concentration of TCGF produced by mitogen-stimulated PBL from old as compared with young donors was due to a suppression of TCGF production in the old donor cultures. To investigate this possibility, TCGF production and ${ }^{3} \mathrm{H}-\mathrm{Tdr}$ incorporation were measured in the PHA-stimulated lymphocyte cultures from either old or young persons and compared to responses observed in mixed cultures containing equal numbers of PBL from both old and young donors. As shown in Table III TCGF production and ${ }^{3} \mathrm{H}-\mathrm{Td} \mathrm{dr}-$ incorporation responses in mixed cultures (containing cells from both old and young donors) observed were those predicted from the TCGF activity found or ${ }^{3} \mathrm{H}$ Tdr incorporated by either cell population cultured alone. For example, a 48-h culture supernatant fluid, conditioned by PHA-stimulated PBL from elderly subject 276, had $1.0 \mathrm{U} / \mathrm{ml}$ TCGF activity, whereas medium from identical cultures conditioned by PBL from young subject $\mathrm{KAH}$ contained $12.9 \mathrm{U} / \mathrm{ml}$ TCGF. Cultures containing equal numbers of cells (same final concentration of cells) from both donors yielded a supernatant medium containing $6.7 \mathrm{U} / \mathrm{ml}$ of TCGF activity. Culture of KAH PBL at $1 / 2$ the normal concentration $\left(5 \times 10^{5}\right.$ cells $/ \mathrm{ml}$ as opposed to $10^{6}$ cells $\left./ \mathrm{ml}\right)$ generated only half the quantity of TCGF $(6.3 \mathrm{U} / \mathrm{ml})$. 
TABLE III

PBL from Old Donors Do Not Suppress TCGF Production or ${ }^{3} \mathrm{H}-\mathrm{Tdr}$ Incorporation Response of PBL from Young Donors*

\begin{tabular}{lcc}
\hline \multicolumn{1}{c}{ PBL donors } & TCGF activity & ${ }^{3} \mathrm{H}-\mathrm{Tdr}$ incorporation \\
\hline & U/ml & $c p m \times 10^{-3}$ \\
A-276 & 1.0 & $67.7 \pm 1.9$ \\
A-76 & 3.5 & $88.1 \pm 6.2$ \\
Y-KAH & 12.9 & $139.1 \pm 5.8$ \\
A-276 + Y-KAH & 6.7 & $98.2 \pm 1.9$ \\
A-76 + Y-KAH & 7.5 & $112.3 \pm 1.0$ \\
A-276 + A-76 & 2.6 & $79.1 \pm 0.8$ \\
Y-KAH $\$$ & 6.5 & $78.7 \pm 1.4$ \\
\hline
\end{tabular}

* Lymphocytes from aged (A) or young (Y) donors were incubated alone or with PHA. TCGF concentration in supernatant medium from cultures was measured after $48 \mathrm{~h}$. ${ }^{3} \mathrm{H}-\mathrm{Tdr}$ was measured after $68 \mathrm{~h}$ incubation. Except for one culture, the final concentration of cells was $10^{6} / \mathrm{ml}$ medium.

f Final concentration of cells $5 \times 10^{5}$ cells $/ \mathrm{ml}$.

Thus, the impaired capacity of PBL from elderly donors to produce TCGF did not appear to be the result of suppression of TCGF production.

\section{DISCUSSION}

We have presented evidence that lymphocyte cultures from elderly individuals incubated with PHA or Con A do not have as much TCGF in the medium as similar cultures from young persons. Furthermore the augmentation of ${ }^{3} \mathrm{H}-\mathrm{Tdr}$ incorporation seen when TCGF was added to lymphocyte cultures from young people was not found when TCGF was added to cultures from old donors. Finally, mitogen-activated lymphocytes from elderly donors did not absorb as much TCGF as did lymphocytes from young donors. The concentration of TCGF in culture medium depends upon both the production and the consumption of TCGF by activated T lymphocytes (5-7). Because stimulated elderly lymphocytes did not respond well to TCGF in culture and did not bind more TCGF than young stimulated $T$ cells, we concluded that the concentration of TCGF present in culture medium conditioned by PHA or Con-A-activated elderly PBL reflects a true decrease in production of TCGF. The impaired production of TCGF by PBL from elderly donors did not reflect active "suppression" of TCGF production. TCGF activity in medium from mixed cultures (containing PHA-activated lymphocytes from both old and young donors) was that predicted from the mixture of TCGF containing supernatant fluids produced by lymphocytes from old and young subjects cultured separately.

These results may explain the cellular defects previously observed: (a) decreased numbers of mitogen-re- sponsive lymphocytes and $(b)$ impaired proliferation of such mitogen-responsive cells. The number of lymphocytes that proliferate when cultured with mitogen depends on the number of cells that can be stimulated by mitogen to express a responsiveness for TCGF, the driving force for $\mathrm{T}$ cell division. Presumably such responsiveness is mediated by acquisition of a normal number of high affinity cell surface TCGF receptors $(5-7,12,13)$. Our results suggest that fewer $T$ cells from elderly people acquire TCGF receptors of sufficient number or affinity to mediate a cellular response to TCGF. This may explain the presence of fewer mitogen-responsive lymphocytes in the blood of elderly people (3). There is no evidence that binding of PHA by lymphocytes from elderly mice is decreased with age (17). Preliminary studies in our laboratory have shown that the number and affinity of PHA receptors on $\mathrm{T}$ lymphocytes from young and old human donors are the same.

The impaired capacity of mitogen-responsive lymphocytes from old persons to divide in culture has recently been directly assessed in our laboratory using bromodeoxyuridine quenching of chromatid fluorescence (18). This technique permits the identification of cells dividing for the first, second, or third time in culture. Cultures of lymphocytes from elderly persons incubated for $72 \mathrm{~h}$ with PHA contained the same number of lymphocytes dividing from the first time but less than $1 / 2$ the number of cells dividing a second time and less than $1 / 4$ the number of cells dividing for a third time found in cultures of lymphocytes from young persons. This was not because of a delayed response to PHA or prolonged cell cycle in cultures from aged humans. The decreased production of TCGF in cultures from old persons may be an important factor limiting the successive division of $T$ lymphocytes.

At this time we can not identify the cellular or subcellular basis for the impairments in TCGF production. TCGF production depends on the activity of both monocytes and $T$ lymphocytes (19). Because there is little evidence that monocyte function is comprised with age (20), the cellular basis of the impaired production of TCGF must await further study. The impaired production of TCGF may reflect the loss of a cell population or an intracellular defect in the biosynthetic pathway of TCGF.

\section{ACKNOWLEDGMENTS}

This work was supported in part by grants from the National Leukemia Association, Inc., and grants CA-19052, AG 00541, and AG 00239 from the National Institutes of Health, U. S. Public Health Service.

\section{REFERENCES}

1. Weksler, M., and T. H. Hutteroth. 1974. Impaired lymphocyte function in aged humans. J. Clin. Invest. 53: 99-104. 
2. Gupta, S., and R. A. Good. 1979. Subpopulation of human $\mathrm{T}$ lymphocytes $\mathrm{X}$. Alterations in T, B third population cells and $T$ cell with receptors for immunoglobulin $M(T \mu)$ or $\mathrm{G}(\mathrm{T} \gamma)$ in aging humans. J. Immunol. 122: 1214-1219.

3. Inkeles, B., J. B. Innes, M. M. Kuntz, A. S. Kadish, and M. E. Weksler. 1977. Immunological studies of aging. III. Cytokinetic basis for the impaired response of lymphocytes from aged humans to plant lectins. J. Exp. Med. 145: 1176.

4. Gillis, S., P. E. Baker, F. W. Ruscetti, and K. A. Smith. 1978. Long-term culture of human antigen-specific cytotoxic T-cell lines. J. Exp. Med. 148: 1093.

5. Smith, K. A., S. Gillis, and P. E. Baker. 1979. The role of soluble factors in the regulation of $\mathrm{T}$-cell immune reactivity. Proceedings of the Thirteenth Leukocyte Culture Conference. Academic Press, Inc., New York. In press.

6. Smith, K. A., S. Gillis, F. W. Ruscetti, P. E. Baker, and D. McKenzie. 1979. T-cell growth factor: the second signal in the T-cell immune response. Proc. N. Y. Acad. Sci. 332: 423.

7. Bonnard, G. D., K. Yasaka, and D. Jacobsen. 1979. Ligand activated $\mathrm{T}$-cell growth factor-induced proliferation: absorption of T-cell growth factor by activated T-cells. J. Immunol. 123: 2704.

8. Gillis, S., and K. A. Smith. 1977. Long-term culture of tumor-specific cytotoxic T-cells. Nature (Lond.). 268: 154.

9. Watson, J., S. Gillis, J. Marbrook, D. Mochizuki, and K. A. Smith. 1979. Biochemical and biological characterization of lymphocyte regulatory molecules. I. Purification of a class of murine lymphokines. J. Exp. Med. 150: 849.

10. Gillis, S., K. A. Smith, and J. Watson. 1980. Biochemical characterization of lymphocyte regulatory molecules. II. Purification of a class of rat and human lymphokines. J. Immunol. 124: 1954.

11. Gillis, S., M. M. Ferm, W. Ou, and K. A. Smith. 1978.
T-cell growth factor: parameters of production and a quantitative microassay for activity. J. Immunol. 120: 2027.

12. Coutinho, A., E-L. Larrson, L. O. Gronuck, and J. Andersson. 1979. Studies on T-lymphocyte activation. II. The target cell for concanavalin-A-induced growth factors. Eur. J. Immunol. 9: 587.

13. Gillis, S., and M. Scheid. 1980. Identification and phenotypic characterization of T-cell growth factor producing Tlymphoma cell lines. J. Supramol. Struct. 4: 135.

14. Gillis, S., G. R. Crabtree, and K. A. Smith. 1979. Glucocorticoid-induced inhibition of T-cell growth factor production. I. The effect on mitogen-induced lymphocyte proliferation. J. Immunol. 123: 1625.

15. Gillis, S., G. R. Crabtree, and K. A. Smith. 1979. Glucocorticoid-induced inhibition of T-cell growth factor production. II. The effect on the in vitro generation of cytolytic T-cells. J. Immunol. 123: 1633.

16. Smith, K. A., P. E. Baker, S. Gillis, and F. W. Ruscetti. 1980. Molecular and functional characteristics of T-cell growth factor. Mol. Immunol. 17: 579.

17. Callard, R. E., and A. Basten. 1977. Immune function in aged mice I. T-cell responsiveness using phytohemagglutinin as a functional probe. Cell. Immunol. 31: 13-25.

18. Hefton, J. M., G. Darlington, B. A. Casazza, and M. E. Weksler. 1980. Immunological studies of aging. V. Impaired proliferation of PHA responsive human lymphocytes in culture. J. Immunol. 125: 1007.

19. Larrson, E. L., N. N. Iscove, and A. Coutinho. 1980. Two distinct factors are required for induction of T-cell growth. Nature (Lond.). 233: 644.

20. Heidrick, M. D., and T. Makinodan. 1973. Presence of impairment of humoral immunity in non-adherent spleen cells of old mice. J. Immunol. 111: 1502. 